\title{
Fracture simulation of CFRP laminates in mixed mode bending
}

\author{
P. Naghipour ${ }^{\mathrm{a}, \mathrm{b}, *}$, J. Schneider ${ }^{\mathrm{a}}$, M. Bartsch ${ }^{\mathrm{a}}$, J. Hausmann ${ }^{\mathrm{a}}$, H. Voggenreiter ${ }^{\mathrm{a}, \mathrm{b}}$ \\ a Institute of Material Research, German Aerospace Center (DLR), Cologne, Germany \\ ${ }^{\mathrm{b}}$ Institute of Aircraft Design (IFB), University of Stuttgart, Stuttgart, Germany
}

\section{A R T I C L E I N F O}

\section{Article history:}

Received 26 September 2008

Received in revised form 4 March 2009

Accepted 5 May 2009

Available online $\mathrm{xxxx}$

\section{Keywords:}

Mixed mode delamination

Cohesive zone modelling

Crack tip element

Polymer matrix composites

\begin{abstract}
A B S T R A C T
This paper analyses the progressive mixed mode delamination failure in unidirectional and multidirectional composite laminates using fracture experiments, finite element (FE) simulations and an analytical solution. The numerical model of the laminate is described as an assembly of damageable layers and bilinear interface elements subjected to mixed mode bending. The analytical approach is used to estimate the total mixed mode and decomposed fracture energies for laminates with different stacking sequences, which is also validated through experiments. It is concluded that the interlaminar fracture toughness of multidirectional laminates is considerably higher than that of the unidirectional ones. The effect of initial interfacial stiffness and element size is studied and it is also shown that their value must not exceed a definite limit for the numerical simulations to converge. The model can also be further extended to simulate the mixed mode fracture in hybrid fiber metal laminates.
\end{abstract}

() 2009 Elsevier Ltd. All rights reserved.

\section{Introduction}

Failure in laminated composites has been one of the major issues being studied extensively in recent years as they are widely used in industrial applications. Fiber reinforced composites often exhibit complex failure mechanisms as an interaction of intralaminar damage modes such as matrix cracking and fiber rupture and interlaminar damage modes, predominantly delamination. Interfacial cracking between layers or delamination can be a result of impact, bearing load in bonded joints, or any other source of significant interlaminar stress. Hybrid Ti/CFRP laminates, composed of titanium (Ti) layers with multidirectional Carbon Fiber Reinforced Plastic (CFRP) plies in between, are being developed to satisfy the requirements for future aerospace applications. In order to simulate the mixed-mode damage mechanism of Ti/CFRP laminates it is essential to develop the correct damage model of each of the constituents, especially CFRP. As various factors such as fiber orientations, different stacking sequences and combination of inter- and intralaminar damage modes might affect the damage mechanism in CFRP, more complexity is involved in the mechanical behaviour of this constituent of the hybrid laminate. Hence, this work thoroughly focuses on the analysis of the mixed-mode damage in the CFRP part.

In case of predominant intralaminar damage modes, a detailed orthotropic ply damage model must be developed to fully capture the failure mechanism [1-5]. When interlaminar failure or delamination is of primary concern, several methods suggested in literature can be used for simulating interfacial damage initiation and propagation [6-17]. Most analyses of delamination growth initially applied a fracture mechanics approach and evaluate energy release rates $G$ using the $J$-integral [6] or virtual crack closure technique (VCCT) [7]. However the use of VCCT may require complex moving mesh techniques to advance the crack front when the local energy release rates reach a critical value. Recently one of the more appealing techniques found in the literature, which can overcome the above-mentioned difficulty, is the cohesive zone approach. A

\footnotetext{
* Corresponding author. Address: Institute of Material Research, German Aerospace Center (DLR), Cologne, Germany. Tel.: +49 2203 6013509.

E-mail address: parya.naghipour@dlr.de (P. Naghipour).
} 


\section{Nomenclature}

$\begin{array}{ll}a & \text { crack length } \\ b & \text { length of the uncracked region in crack tip element } \\ c & \text { loading lever length } \\ d & \text { isotropic damage parameter of the interface } \\ h & \text { thickness of each delamination arm } \\ K & \text { initial stiffness of the interface } \\ L & \text { half length of the specimen } \\ P & \text { applied load } \\ W & \text { specimen width } \\ A_{i j} & \text { extensional stiffness of the laminate } \\ B_{i j} & \text { coupling stiffness of the laminate } \\ d_{f} & \text { orthotropic ply damage parameter in fiber direction } \\ d_{m} & \text { orthotropic ply damage parameter transverse to fiber direction } \\ d_{s} & \text { orthotropic ply damage parameter in shear direction } \\ D_{i j} & \text { bending stiffness of the laminate } \\ E_{1 f} & \text { flexural modulus of the laminate in fiber direction } \\ E_{11} & \text { longitudinal ply modulus } \\ E_{22} & \text { transverse ply modulus } \\ G_{12} & \text { in plane shear modulus of a ply } \\ G_{\text {Ic }} & \text { mode I critical strain energy release rate } \\ G_{I I c} & \text { mode II critical strain energy release rate } \\ N_{i} & \text { external forces acting on the laminate } \\ M_{i} & \text { external moments acting on the laminate } \\ N_{c i} & \text { external forces acting on the cracked region of crack tip element } \\ M_{c i} & \text { external moments acting on the cracked region of crack tip element } \\ S & \text { ultimate in-plane strength shear directions, respectively } \\ X & \text { ultimate in-plane strength in fiber direction } \\ Y & \text { ultimate in-plane strength in transverse direction } \\ v_{12} & \text { in-plane ply Poisson's ratio } \\ \chi & \text { crack tip correction factor } \\ \tau_{i} & \text { interface tractions } \\ \delta_{i} & \text { interface displacement discontinuities } \\ \delta l & \text { length of the interface element } \\ & \end{array}$

further advantage of the approach is that it does not need the exact specification of the initial crack tip position, especially in cases where the crack did not exist previously. Cohesive zone model was first suggested by Dugdale [8], and later Barenblatt [9] and Hillerborg et al. [10] added significant contributions to it. Since then, many authors have published papers on the cohesive zone approach or development of interface elements [11-17].

In order to improve the interlaminar fracture resistance of fiber reinforced composites, multidirectional (MD) laminates, with different ply orientations, are generally preferred to unidirectional (UD) ones. The behaviour of different MD composite laminates subjected to single or mixed mode delamination has been studied by different research groups [18-32]. Different stacking sequence, fiber orientations and crack propagation directions have considerable effects on the structural response and fracture toughness of the specimen subjected to delamination. Enhanced interlaminar fracture resistance of laminates with dissimilar fiber orientations has been approved experimentally in Refs. [22-25]. The total mixed mode fracture toughness of these laminates can also be predicted following the analytical crack tip element (CTE) approach [26-28], incorporating classical laminated plate theory (CLPT) and Irwin's virtual crack closure method in the neighbourhood of a very short segment of the delamination edge. The CTE approach is then combined with the non-singular filed (NSF) approach [28] to further decompose the fracture energy to its non-classical mode I and mode II components. Due to extrinsic toughening mechanisms such as blunted crack tips or deviation of the crack from the main crack plane to the adjacent layers, higher resistance to through thickness fracture is observed in MD laminates [22,23,29-31].

The present paper focuses on simulation of mixed mode delamination in UD and MD composites following experimental, numerical, and analytical approach. Comprehensive incorporation of these three approaches all together on various MD and UD layups, providing a detailed analysis tool of the mixed mode failure mechanism, has not been addressed earlier in literature and is the main scope of this work. The mixed mode bending (MMB) experiments, first suggested by Crews and Reeder [33,34], are conducted at German Aerospace Centre (DLR) to obtain the load-displacement response and thoroughly analyze the interlaminar fracture mechanisms of different UD and MD laminates under various mode mixities. The followed numerical approach is based on the use of damageable plies and user defined interface elements. An in-built ply damage model in ABAQUS [35], partially based on the works of Hashin [5] and Matzenmiller at al. [2], is used to define the intralaminar ply 
damage behaviour. Meanwhile the mixed mode delamination damage is represented by using interface elements, the constitutive mathematical model of which is described in detail in Ref. [16]. The numerical model is validated by reproducing the load-displacement response of the conducted MMB experiments and growth of the expected damage. The above-mentioned combined analytical CTE/NSF approach is followed for different MD and UD laminates to obtain an initial estimation of the total interlaminar fracture toughness, to decompose the fracture energy to non-classical mode I and II components and later to be compared with experimental results.

Following this introduction, Section 2 describes the material system, the MMB experimental procedure, and the CTE/NSF routine used to estimate the total interlaminar energy release rates and mode decompositions of various laminates. The numerical procedure is summarized in Section 3, first as a very brief summary of the used ply damage model, followed by the governing equations and the constitutive behaviour of the interface element and required input material parameters. Comparisons between numerical, experimental and analytical results and also the effect of some interface parameters on the load-displacement response are all given in the Results and Discussion part in Section 4. Finally a brief summary and conclusions is presented in Section 5.

\section{Experimental program}

\subsection{Test specimen}

Base material used in this study is APC2-prepreg material from Cytec Engineered Materials (Cytec Industries Inc.) consisting of AS4-fibres (60 vol.\%) impregnated with a PEEK matrix. The thickness of each prepreg layer is about $140 \mu \mathrm{m}$. The number and orientation of layers, as given in Table 1, is stacked together on a heating plate. To obtain a defined delamination according to ASTM D6671 a $50 \mathrm{~mm}$ width polyimide film $\left(\operatorname{Kapton}^{\circledR}\right)$ is placed in the midplane of each lay-up as a delamination starter. The completed stacking is equipped with thermocouples and covered with a vacuum bag and textile insulation layers. After applying vacuum, the heating plate is heated up to $400^{\circ} \mathrm{C}$ to melt the PEEK matrix for consolidation. Then the heating is switched off for cooling down. After removing the insulation and vacuum bag a consolidated plate with the desired lay-up and delamination layer is obtained. Plates with a dimension of about $320 \times 320 \mathrm{~mm}^{2}$ were produced and cut by water jet to final specimen size (24-ply carbon/PEEK laminate, $25 \mathrm{~mm}$ wide, $150 \mathrm{~mm}$ long, and $3.12 \mathrm{~mm}$ thick). Thus, several specimens were produced within one batch. The production of all specimens using the above-mentioned consolidation technique was held at the composite laboratory of German Aerospace Centre (DLR). The stacking sequence of the multidirectional specimens is chosen according to the available research works in literature [18-25]. In order to minimize the effect of thermal residual stresses, as the specimens are tested at a temperature different from the cure temperature, coupling stiffness $\left(B_{i j}\right)$ of the chosen laminates is desired to be zero or very close to zero [22,36]. Meanwhile balanced stacking sequences, which have equal numbers of $+\theta$ and $-\theta$ plies, are preferred. According to Kruger and Konig [18] the amount of crack front curvature correlates to the magnitude of a non-dimensional ratio $D_{c}=\left(D_{12}\right)^{2} / D_{11} D_{22}$, where $D_{i j}$ are the elements of the bending stiffness matrix of the sublaminates. It has been proposed that the specimen stacking sequence should be chosen to minimize and keep $D_{c}$ smaller than 0.25 in each delamination arm. It has been also shown that minimization of $D_{c}$ will also minimize the non-uniform toughness value distribution, local mixed mode effects, skewed and curved crack fronts in fracture testing, and the errors in the perceived values of critical fracture toughness obtained from experimental load-deflection data $[18,19,22]$. Hence the produced layups have mainly balanced configuration, the value of $D_{c}$ is kept under 0.25 and $B_{i j}$ close to zero, for all of them. The detailed specimen stacking sequences are shown in Table 1.

\subsection{Experimental procedure and data reduction}

Typically, delamination failures in composite laminates initiate and propagate under the combined influence of normal and shear stresses. Crews and Reeder [33,34] addressed delamination testing with combined tensile normal stress (mode I) and sliding shear stress (mode II) in their study. The MMB loading was represented by a superposition of simple mode I and mode II loadings [37,38], conducted by a single load $P$. Fig. 1 shows a picture of an actual conducted test and the MMB loading expressed in terms of the applied load $P$, the loading lever length $c$, and the specimen half-span $L$. The loading position $c$ determines the relative magnitude of the two resulting loads on the specimen and therefore, determines the mixed mode delamination ratio. Pure mode II loading occurs when the applied load is directly above the beam mid-span $(c=0)$ and pure mode I loading can be achieved by removing the beam and pulling up on the hinge. The mechanical tests for the both UD and MD specimens were carried out according to the standardized test for mixed mode bending fracture

Table 1

MD and UD CFRP specimen configurations ( $d$ stands for delamination plane).

\begin{tabular}{lll}
\hline Layups to be considered & Layup name & Largest $B_{i j}$ \\
\hline$(+22.5 /-22.5)_{\mathrm{s} 12}$ & $D_{c}$ & Layup 22.5 \\
$+30 /-30 / 0_{3} /-30 / 0 /+30 / 0_{2} /+30 /-30 / \mathrm{d} / 30 /-30 / 0_{2} /+30 / 0 / 30 / 0_{3} /-30 / 30$ & Layup 30 & 0.221 \\
$+45 /-45 / 0_{3} /-45 / 0 /+45 / 0_{2} /+45 /-45 / \mathrm{d} / 45 /-45 / 0_{2} /+45 / 0 / 45 / 0_{3} / 45 /-45$ & Layup 45 & 0.218 \\
Quasi-isotropic $\left([0 / \pm 45 / 90]_{\mathrm{S} 3}\right)$ & Layup QI & 0.230 \\
UD $\left([0]_{24}\right)$ & Layup UD & 0.075 \\
\hline
\end{tabular}



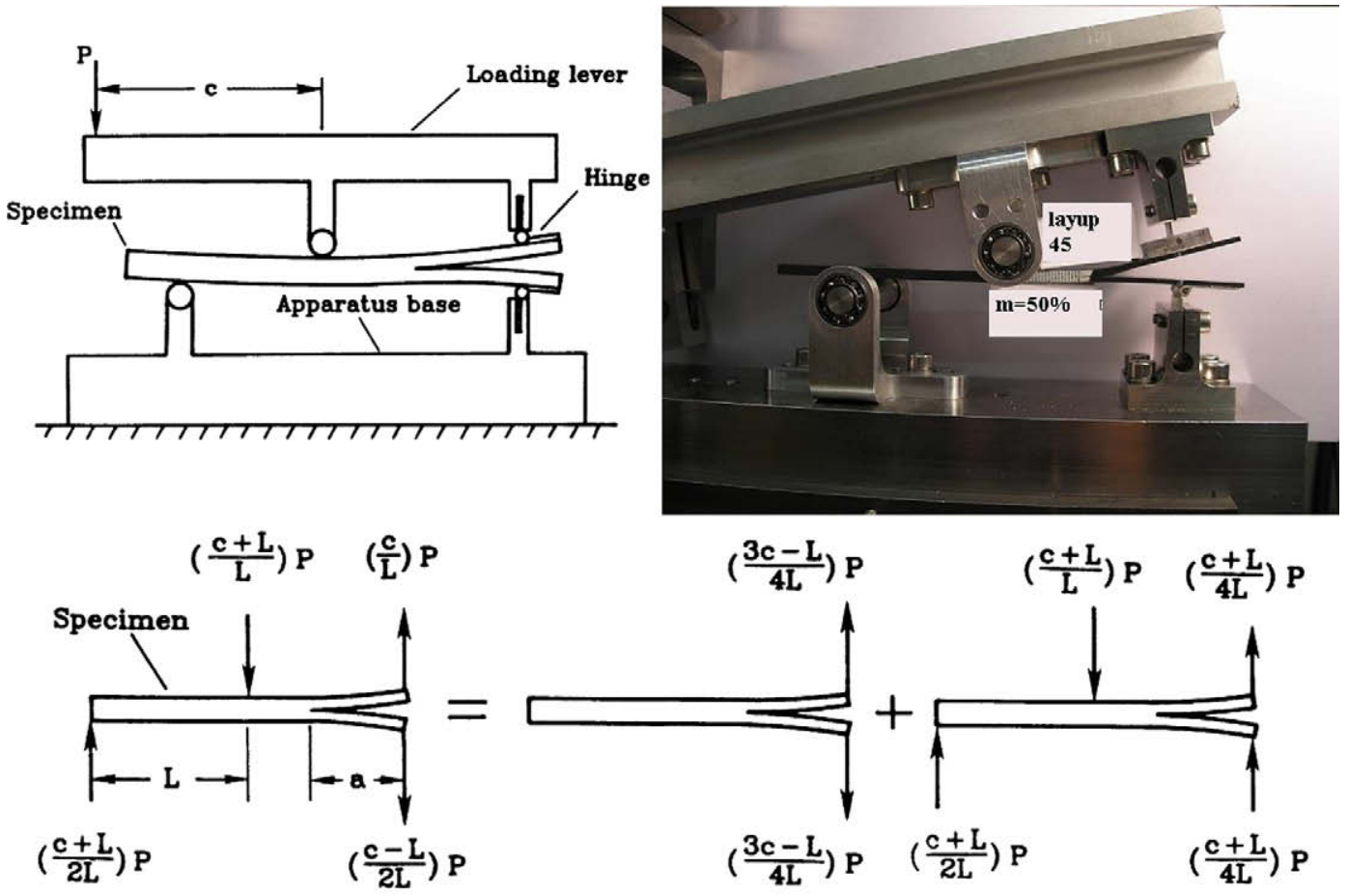

(a) MMB specimen loading.

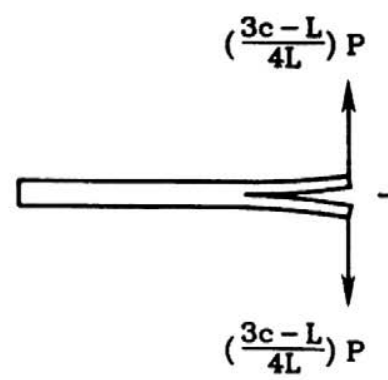

(b) Mode I loading.

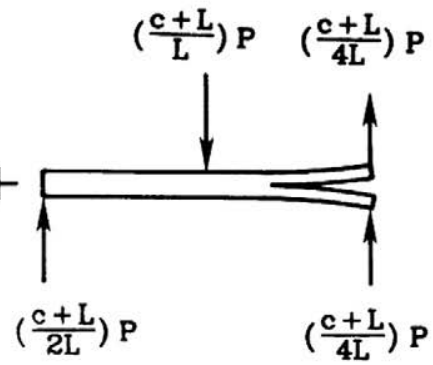

Fig. 1. Schematic and loading description of MMB test apparatus [33].

of fiber reinforced composites [39]. The machine used is a 10 tons Instron testing machine equipped with $100 \mathrm{kN}$ load cells to measure the load for propagating the crack. All the specimens were $150 \mathrm{~mm}$ long, $25 \mathrm{~mm}$ wide, and $3.12 \mathrm{~mm}$ thick, with an initial delamination length of $50 \mathrm{~mm}$ placed at their mid-plane. In addition to pure mode I and pure mode II experiments, mixed mode tests were carried out at three different mode mixities (30\%, 50\%, and 80\%). The cross-head displacement rate was $0.5 \mathrm{~mm} / \mathrm{min}$ for all the specimens. The corresponding loading lever lengths, $c$, for different mode mixities is summarized in Table 2. The loading point displacement and load histories were recorded by using a digital data acquisition system. It is worth mentioning that at least three specimens were tested for each mode mixity, i.e., at each mode mix the average of three experiments is taken as the main experimental data.

The data reduction procedure to calculate mode I and mode II critical strain energy release rates or fracture toughness $\left(G_{I c}\right.$ and $\left.G_{\text {IIC }}\right)$ is summarized here. The solution for mode I and mode II strain energy release rates $\left(G_{I}\right.$ and $\left.G_{\text {III }}\right)$ originate from beam theory equations later corrected by energy associated with shear deformation and the rotation of arms at the delamination tip [37-39]. As it is seen from Eq. (1) $G_{I}$ and $G_{\text {II }}$ are mainly functions of applied load $(P)$, loading lever length $(c)$, propagating crack length (a) (where $\chi$ is the crack tip correction factor [33,34,39-41]) and mechanical and geometrical properties of the specimen ( $w$ : specimen width, $E_{1 f}$ : flexural stiffness in fiber direction, $h$ : thickness of each delamination arm). In the calculation of $G_{I C}$ and $G_{\text {IIC }}$ the critical value of the applied load is chosen as the load corresponding to the 1st visible nonlinearity in load-displacement curve, $\left(P_{\mathrm{NL}}\right)$ [42]. The critical delamination length is the propagation crack length marked through the experiment. Detailed data reductions procedures, formulations, and crack tip and beam theory corrections can be found in Refs. [23,25,39-41]. It is worth mentioning that $G_{\text {IC }}$ and $G_{\text {IIC }}$ values calculated from corrected beam theory [39] are the ones before any deviation of the delamination path from the mid-plan occurs, as this might invalidate the data reduction according to $[37,39-41]$

$$
\begin{aligned}
& G_{\mathrm{I}}=\frac{12 P^{2}(3 c-L)^{2}}{16 W^{2} h^{3} L^{2} E_{1 f}}(a+\chi h)^{2} \\
& G_{\mathrm{II}}=\frac{9 P^{2}(c+L)^{2}}{16 W^{2} h^{3} L^{2} E_{1 f}}(a+0.42 \chi h)^{2}
\end{aligned}
$$

Table 2

\begin{tabular}{|c|c|c|c|c|c|}
\hline $\begin{array}{l}\text { Mode mix } \\
c(\mathrm{~mm})\end{array}$ & $\begin{array}{l}0 \text { (pure mode I) } \\
\text { Lever removed }\end{array}$ & $\begin{array}{l}30 \% \\
98.5 \mathrm{~mm}\end{array}$ & $\begin{array}{l}50 \% \\
65 \mathrm{~mm}\end{array}$ & $\begin{array}{l}80 \% \\
42.5 \mathrm{~mm}\end{array}$ & $\begin{array}{l}100 \% \text { (pure mode II) } \\
0\end{array}$ \\
\hline
\end{tabular}

Lever length for each mode mix. 
Failure criteria used in damage evolution process in composite materials, have been based on stress or strain near the crack tip, crack opening displacement, stress intensity factor, or strain energy release rate. Strain energy release rate seems to be a good measure of a material's resistance to delamination extension and most of the suggested failure criteria can be written in terms of critical strain energy release rate or fracture toughness. In this study, in order to accurately account for the variation of fracture toughness as a function of mode ratio in PEEK composites, the mixed-mode criterion proposed by Benzeggagh and Kenane (B-K criterion, Eq. (2)) [43] is used

$$
G_{\mathrm{Ic}}+\left(G_{\mathrm{II} c}-G_{\mathrm{Ic}}\right)\left(\frac{G_{\text {shear }}}{G_{\mathrm{T}}}\right)^{\eta}=G_{c} \quad G_{\mathrm{T}}=G_{\mathrm{I}}+G_{\text {shear }} \quad G_{\mathrm{T}} \text { : Total fracture toughness }
$$

According to [43] the mixed-mode failure response of the material is described by plotting the total critical fracture toughness $G_{c}$ vs. different mode mixities $\left(G_{\text {shear }} / G_{\mathrm{T}}\right.$ ). Parameter $\eta$ in Eq. (2) maintains the shape of the failure locus in the mixed mode plane and the most accurate failure criterion is the one matching the material response when plotted on this mixed mode diagram.

\subsection{Crack tip element/non-singular field (CTE/NSF) approach}

Previous investigations indicate that the experimentally determined critical energy release rate at any mode mix is sensitive to the ply orientations at the interface. Thus, it is of considerable importance to evaluate the fracture toughness, $G_{c}$ correctly at interfaces with dissimilar ply orientations. Moreover, a reliable MMB numerical simulation requires a correct evaluation of $G_{c}$ specially in between disoriented plies. Scharpery and Davidson [26] suggested the CTE approach, for the prediction of total energy release rate for mixed mode delamination. This approach starts with finding mid plane strains $\left(\varepsilon_{x}, \varepsilon_{y}\right.$, $\left.\varepsilon_{x y}\right)$ and midplane curvatures $\left(\kappa_{x}, \kappa_{y}, \kappa_{x y}\right)$ according to the external known load case (MMB here). The CLPT equation set (Eq. (3)) is solved for each aforementioned stacking sequence and the mid plane displacements are found

$$
\begin{aligned}
& {\left[N_{i}\right]=\left[\begin{array}{c}
N_{x} \\
N_{y} \\
N_{x y}
\end{array}\right]=\left[A_{i j}\right]\left[\varepsilon_{j}\right]+\left[B_{i j}\right]\left[\kappa_{j}\right]} \\
& {\left[M_{i}\right]=\left[\begin{array}{c}
M_{x} \\
M_{y} \\
M_{x y}
\end{array}\right]=\left[B_{i j}\right]\left[\varepsilon_{j}\right]+\left[D_{i j}\right]\left[\kappa_{j}\right]}
\end{aligned}
$$
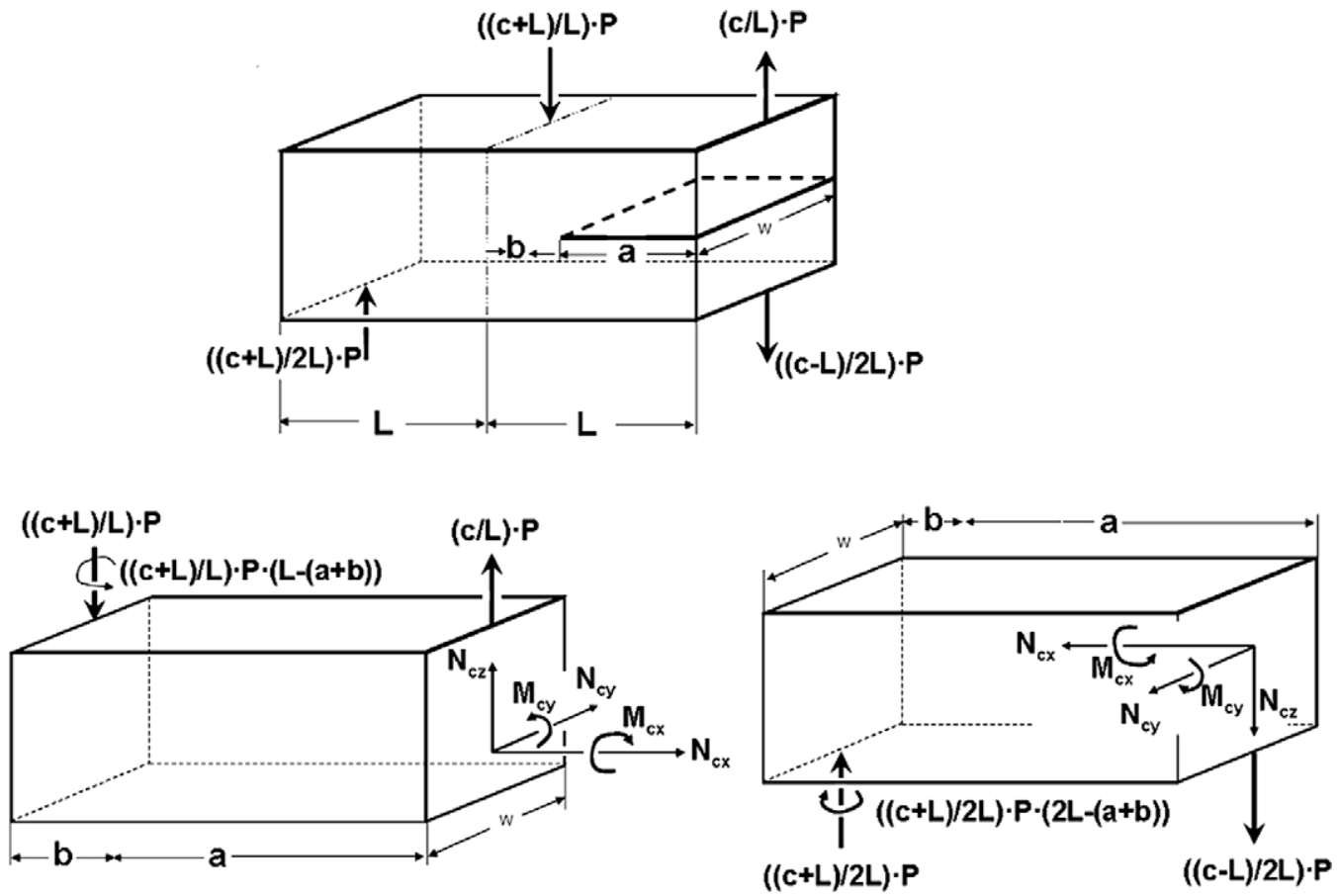

Fig. 2. Free body diagrams of the upper (left) and lower (right) half for the crack tip element. 


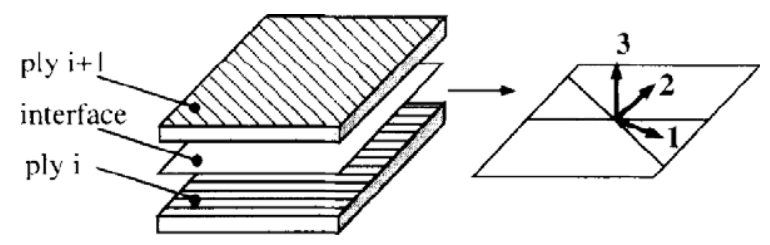

Fig. 3. Schematic of the numerical model (lamina + interface) [4].

According to Jone's notation [36] $A_{i j}, B_{i j}$ and $D_{i j}$ stand for extensional, coupling and flexural stiffness of the laminate, and $N_{j}$ and $M_{j}$ are externally acting forces and moments. The next step is defining the crack tip element (Fig. 2). This element represents a three-dimensional portion of the crack tip region in a general interfacial fracture problem. The lengths of the element is large enough with respect to its thickness, but still sufficiently small for geometric nonlinearities to be negligible. Thus, classical plate theory can be used to predict the overall deformation and strain energies of the element. The crack tip element is then divided to two upper and lower sub laminates and the crack tip strains, curvatures, and internally induced crack tip forces and moments are obtained in the upper and lower cracked regions.

Internally induced crack tip forces $\left(N_{c x}, N_{c y}, N_{c x y}\right)$ and moments $\left(M_{c x}, M_{c y}, M_{c x y}\right)$ and mid plane strains and curvatures in upper and lower sublaminates are summarized in Eq. (4). As mentioned in [27] the constraint of the uncracked region along the left edge of the plate in Fig. 3 limits the deformations and therefore the mid plane strains of cracked sublaminates are reduced to $\varepsilon_{x}, \varepsilon_{x y}$ and $\kappa_{x}$. $\left(B_{i j} j^{\prime}\right.$ and $D_{i} j^{\prime}$ stand for inverse of $B_{i j}$ and $D_{i j}$ matrices, respectively, and $P$ is the force per unit area here).

$$
\begin{aligned}
& {\left[\begin{array}{c}
N_{c x} \\
N_{c y} \\
N_{c x y}
\end{array}\right]=\left[\begin{array}{c}
N_{x} \\
N_{y} \\
N_{x y}
\end{array}\right]^{\text {upper }}=0\left[\begin{array}{l}
M_{c x} \\
M_{c y} \\
M_{c x y}
\end{array}\right]=\left[\begin{array}{c}
N_{c x} \\
N_{c y} \\
N_{c x y}
\end{array}\right](t / 4)+\left[\begin{array}{c}
M_{x} \\
M_{y} \\
M_{x y}
\end{array}\right]^{\text {upper }}=\left[\begin{array}{c}
\frac{c+L}{L} P L \\
0 \\
0
\end{array}\right]^{\text {upper }}} \\
& {\left[\begin{array}{c}
\varepsilon_{x} \\
\varepsilon_{x y} \\
\kappa_{x}
\end{array}\right]^{\text {upper }}=\left[\begin{array}{l}
B_{11}^{\prime} M_{c x} \\
B_{61}^{\prime} M_{c x} \\
D_{11}^{\prime} M_{c x}
\end{array}\right]^{\text {upper }}\left[\begin{array}{c}
\varepsilon_{x} \\
\varepsilon_{x y} \\
\kappa_{x}
\end{array}\right]^{\text {lower }}=\left[\begin{array}{l}
-B_{11}^{\prime} M_{c x} \\
-B_{61}^{\prime} M_{c x} \\
-D_{11}^{\prime} M_{c x}
\end{array}\right]^{\text {lower }}}
\end{aligned}
$$

The 3rd step is expressing the energy release rate $\left(G_{c}\right)$ in upper and lower parts in terms of the crack tip internal forces and displacements:

$$
G_{c}=\frac{1}{2 b}\left(N_{c i} \Delta u_{i}+M_{c i} \Delta \theta_{i}\right)=\frac{1}{2 b}\left(M_{c x} \Delta \theta_{x}\right)=\frac{1}{2 b} M_{c x} b\left(\Delta \kappa_{x}\right)=\frac{1}{2 b} M_{c x} b\left(\kappa_{x}^{\text {upper }}-\kappa_{x}^{\text {lower }}\right)=\frac{1}{2} M_{c x}\left(2 M_{c x} D_{11}^{\prime}\right)=M_{c x}^{2} D_{11}^{\prime}
$$

The whole procedure is followed for each stacking sequence mentioned previously in a FORTRAN routine and the results are summarized in Section 4 (Table 4). The energy release rate derived analytically, following this procedure, gives a good approximation of the fracture toughness variability with respect to different fiber orientations and layups.

As predicting the accurate mode mix is quite important for MD specimens with delaminations between differently oriented plies, the mode decomposition of the total energy release rate must be determined accurately. Davidson et al. [44] performed the non-classical "crack tip element/non-singular field" (CTE/NSF) approach to decompose the obtained energy release rates to non-classical mode I and mode II components. The method is shown to provide relatively accurate mode mix predictions for various composites. In the CTE/NSF approach the plate theory parameters such as concentrated crack tip forces and moments, $N_{c}$ and $M_{c}$, can best be used to also characterize the mode mix (Eq. (5)). As mentioned in the CTE approach, $N_{c}$ and $M_{c}$ are known functions of the remote loading, the laminate geometry, the stacking sequence and ply properties. The mode mix defined in $[28]$ as $G_{\mathrm{II}} / G_{\mathrm{T}}$ is given by:

$$
\frac{G_{I I}}{G}=\frac{\left[N_{c} \sqrt{c_{1}} \cos \Omega+M_{c} \sqrt{c_{2}} \sin (\Omega+\Gamma)\right]^{2}}{c_{1} N_{c}^{2}+c_{2} M_{c}^{2}+2 \sqrt{c_{1} c_{2}} N_{c} M_{c} \sin \Gamma} \sin \Gamma=\frac{c_{12}}{\sqrt{c_{1} c_{2}}}
$$

In Eq. (5) the mode mix $\left(G_{\mathrm{II}} / G_{\mathrm{T}}\right)$ is defined as a function of $N_{c}, M_{c}, c_{1}, c_{2}, c_{12}$ and $\Omega . c_{1}, c_{2}$ and $c_{12}$, defined in detail in Refs. [28,45], are mainly functions of stacking sequence and geometry of each laminate. The mode mix parameter $\Omega$ is given in Eq. (6), as expressed in [44]:

$$
\Omega=\left\{\begin{array}{ll}
-24 & \text { if } \log \left(t_{2} / t_{1}\right)<-0.468 \\
60.409 \log \left(t_{2} / t_{1}\right)-41.783\left(\log \left(t_{2} / t_{1}\right)\right)^{3} & \text { if }-0.468<\log \left(t_{2} / t_{1}\right)<0.468 \\
24 & \text { if } \log \left(t_{2} / t_{1}\right)>0.468
\end{array}\right\}
$$

Davidson et al. [44] verified that the expressions for mode mix and $\Omega$ (Eqs. (5) and (6)) are universally valid and can be used for a wide range of graphite reinforced polymeric matrix composites.

Following this non-classical CTE/NSF approach the first step is to perform fracture tests of UD laminates with midplane delaminations. The MMB toughness for these laminates is obtained using the data reduction scheme suggested in ASTM standard [39] which is summarized in Eq. (1). The mode mixities from these tests are then obtained by the NSF approach using Eq. (5), and these results are graphed to produce delamination toughness, $G_{c}$, versus mode mix, $G_{\mathrm{III}} / G_{\mathrm{T}}$, curve. The graph 
is called basic toughness curve [44]. The second step is to perform MMB fracture tests of MD laminates. As for the tests on UD laminates with midplane delaminations, the MMB toughness is obtained based on the corrected beam theory [39-41]. The mode mixities from these tests are also obtained by the NSF approach, and the results from toughness-mode mix curves are then superimposed on the basic toughness curve. When a unique value of toughness for each mode mixity is obtained for the mentioned UD and MD layups, it can be claimed that the approach has a good predictive accuracy [44]. The CTE/NSF approach is followed for layup UD, layup 22.5 and layup 45 (listed in Table 1) and the accurate predictive capability of this approach is discussed more in detail in Section 4 (Fig. 8).

\section{Numerical simulations}

The numerical model created in ABAQUS [35] consists of individual damageable plies to capture any in-ply damage and interface elements in between them as shown schematically in Fig. 3. The mathematical damage models used for the ply and the interface are described in this section.

\subsection{Ply damage model}

The in-built Hashin damage model in ABAQUS [35] is used to describe the in-ply damage in each lamina. Each ply is defined using an orthotropic material in plane stress. Damage initiation, which refers to the beginning of degradation of the ply response, is due to four main failure criteria, namely: fiber ruptures in tension, fiber buckling in compression, matrix cracking under transverse tension and shearing, and matrix crushing under transverse compression. Damage propagates when the total fracture energy in any of the four mentioned cases reaches its maximum value $\left(G_{c \max }\right)$ specified by the user as an input parameter. After damage initiation, three independent non-negative in-ply damage parameters, $d_{f}, d_{m}$, and $d_{s}$ reduce the ply stiffness numerically in fiber, transverse, and shear directions, respectively, until the final failure point is reached. Therefore, the degradation of the ply stress tensor $(\boldsymbol{\sigma})$ can be written as [2]:

$$
\begin{aligned}
\boldsymbol{\sigma} & =\frac{1}{1-\left(1-d_{f}\right)\left(1-d_{m}\right) v_{12} v_{21}}-\mathbf{C}\left[\begin{array}{c}
\varepsilon_{11} \\
\varepsilon_{22} \\
\varepsilon_{12}
\end{array}\right] \\
\mathbf{C} & =\left(\begin{array}{ccc}
E_{11}\left(1-d_{f}\right) & \left(1-d_{f}\right)\left(1-d_{m}\right) E_{22} v_{21} & 0 \\
\left(1-d_{f}\right)\left(1-d_{m}\right) E_{11} v_{12} & E_{22}\left(1-d_{m}\right) & 0 \\
0 & 0 & 1-\left(1-d_{f}\right)\left(1-d_{m}\right) v_{12} v_{21}\left(1-d_{s}\right) G
\end{array}\right)
\end{aligned}
$$

$E_{11}, E_{22}$, and $G_{12}$ are the longitudinal, transverse and in plane shear modulus of the undamaged orthotropic lamina. Detailed information regarding the mentioned in-ply damage model such as damage evolution laws or constitutive equations can be found in Refs. [2,5,35].

\subsection{Interface model}

The cohesive zone approach adopted in this work makes use of interface finite elements incorporating a cohesive mixedmode damage model. In this section, a concise description of the interface element is given. The zero thickness eight node cohesive elements, implemented as a user element (UEL) in ABAQUS [35], are mainly based on the constitutive model suggested by Davila et al. [16], and the detailed mathematical formulation can be found in Ref. [16].

Fig. 4 shows the global and local geometries of the three-dimensional interface element, which are related by the standard isoparametric mapping. Nodes 1-4 represent lower face of the interface and nodes 5-8, which coincide geometrically with nodes 1-4, represent the upper surface (the zero thickness has been offset for better visualisation).

With respect to the three-dimensional global coordinate system, $x, y, z$, each node has three degrees of freedom, $u, v$ and $w$, respectively. Meanwhile, in the local coordinate system the vector of relative displacements between each pair of the corresponding upper and lower nodes of the element is defined as:

$$
\left[\begin{array}{l}
\delta_{n} \\
\delta_{s} \\
\delta_{t}
\end{array}\right]=\left[\begin{array}{l}
u_{n} \\
u_{s} \\
u_{t}
\end{array}\right]_{\text {TOP }}-\left[\begin{array}{l}
u_{n} \\
u_{s} \\
u_{t}
\end{array}\right]_{\text {воттом }}
$$

where $n$ indicates the opening or normal component and $s$ and $t$ indicate the two shear directions, respectively, as shown in Fig. 4 (right). The damage formulation is based on constitutive interface tractions $\left(\tau_{n}, \tau_{s}, \tau_{t}\right)$ and relative displacements $\left(\delta_{n}, \delta_{s}, \delta_{t}\right)$ as:

$$
\left[\begin{array}{c}
\tau_{s} \\
\tau_{t} \\
\tau_{n}
\end{array}\right]=\underbrace{\left(\left(\begin{array}{ccc}
(1-d) K & 0 & 0 \\
0 & (1-d) K & 0 \\
0 & 0 & (1-d) K
\end{array}\right)+\left[\begin{array}{c}
0 \\
0 \\
d K H\left(-\delta_{n}\right)
\end{array}\right]\right)}_{\mathbf{D}}\left[\begin{array}{c}
\delta_{s} \\
\delta_{t} \\
\delta_{n}
\end{array}\right] H(x)=\left\{\begin{array}{ll}
0 & x<0 \\
1 & x \geqslant 0
\end{array}\right\}
$$




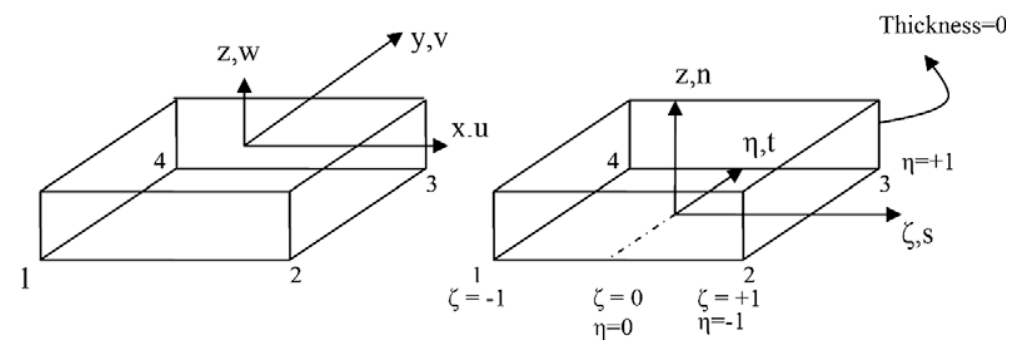

Fig. 4. Interface element with (left) global system and (right) local system.

In Eq. (9), $K$ is the initial stiffness of the interface and $\boldsymbol{D}$ is the constitutive secant tensor with the isotropic damage parameter $d$. Prior to damage initiation, both faces of the interface element are bonded together with the high initial stiffness, $K$, and the value of $d$ is equal to zero. Interface damage initiates based on the quadratic interfacial traction interaction criterion as shown:

$$
\left(\frac{\tau_{n}}{\tau_{n}^{0}}\right)^{2}+\left(\frac{\tau_{s}}{\tau_{s}^{0}}\right)^{2}+\left(\frac{\tau_{t}}{\tau_{t}^{0}}\right)^{2}=1
$$

$\tau_{n}^{0}, \tau_{s}^{0}, \tau_{t}^{0}$ are the normal and shear elastic limits of the interface. The relative displacement corresponding to damage initiation $\left(\delta_{m}^{0}\right)$ in Fig. 5 is called the mixed mode opening displacement or the fictive crack tip. The initiated damage then starts evolving based on an energy based propagation criterion (B-K) [43], which is described in Section 2.2. Meanwhile the isotropic damage parameter degrades the interfacial tractions, as shown in Eq. (9), till the final separation point $\left(\delta_{m}^{f}\right.$, physical crack tip) is reached. The damage evolution law is summarized as

$$
\begin{aligned}
& d=\frac{\delta_{m}^{f}\left(\delta_{m}-\delta_{m}^{0}\right)}{\delta_{m}\left(\delta_{m}^{f}-\delta_{m}^{0}\right)} \\
& \delta_{m}=\sqrt{\delta_{n}^{2}+\delta_{s}^{2}+\delta_{t}^{2}} \\
& \delta_{m}^{0}=\delta_{n}^{0} \delta_{\text {shear }}^{0} \sqrt{\frac{1+m^{2}}{\left(\delta_{\text {shear }}^{0}\right)^{2}+m^{2}\left(\delta_{n}^{0}\right)^{2}}} \delta_{n}>0 \quad m=\frac{\delta_{\text {shear }}}{\delta_{n}} \\
& \delta_{m}^{f}=\frac{2}{K \delta_{m}^{0}}\left[G_{\text {Ic }}+\left(G_{\text {IIc }}-G_{\text {Ic }}\right)\left(\frac{m^{2}}{1+m^{2}}\right)^{\eta}\right] \quad\left(\delta_{n}>0\right)
\end{aligned}
$$

\subsection{FE model description and input material properties for the numerical model}

The numerical model was created using the object oriented ABAQUS Scripting Interface (ASI, python) in ABAQUS [35] for further optimization and parametric studies. The laminate is made of 24 plies with different stacking sequences as defined in Section 2 (Table 1). As mentioned earlier, each lamina is defined using the in-built reinforced ply damage model with eight node, reduced integration, continuum shell elements (SC8R, in ABAQUS). The interface elements, implemented as UEL in ABAQUS [35], are placed in the midplane of the laminate to capture the delamination behaviour. Since the loading lever is not simulated, loading boundary conditions are applied directly to middle and end supports as shown in Fig. 6 . Moreover,

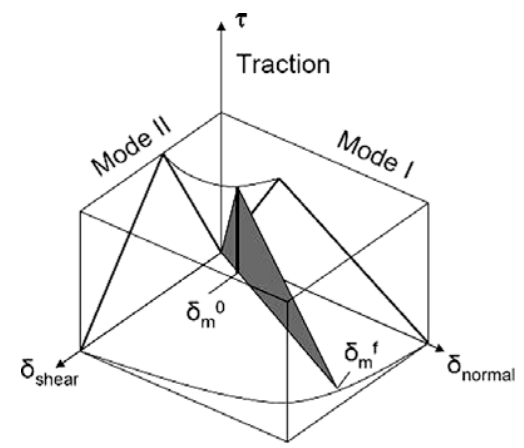

Fig. 5. Schematic of mixed mode softening law in interface elements. 


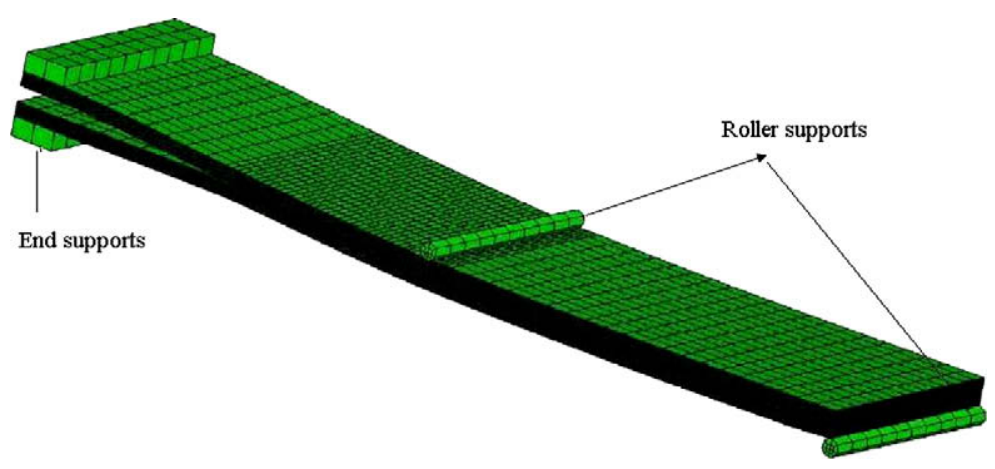

Fig. 6. Schematic view of the numerical model.

different mode mixities, $G_{\mathrm{II}} / G_{\mathrm{T}}$ ratios, are simulated by applying different displacement boundary conditions at mentioned supports. A schematic of the developed numerical model (orthotropic lamina and interface elements and applied boundary conditions) is shown in Fig. 6. Refined mesh is used in the areas near to the middle support and in the vicinity of the delamination plane to avoid any numerical problems like premature ending of the solving due to excessive element deformations.

The input material parameters for each lamina (Table 3a) are obtained from previous measurements [45] $(X, Y$, and $S$ stand for ultimate in-plane strength in fiber, transverse and shear directions, respectively). Laminar fiber fracture and matrix cracking energies were obtained from previously conducted Compact Tension $C(T)$ experimental results $[45,46]$. $C(T)$ experiments had been conducted on $[0 / 90]_{15}$ where one would anticipate fiber breakage, and on $[0]_{30}$ laminates where the mode of failure is generally matrix cracking. The fiber breakage and matrix cracking fracture energies were then calculated by using the data reduction scheme in [46] and reported explicitly in [45]. Interface properties $\left(G_{\mathrm{Ic}}\right.$, $G_{\mathrm{II} c}$, and $\left.\eta\right)$ are found from conducted pure mode and MMB experiments. The 1 st and 2 nd mode interlaminar fracture energies, $G_{I c}$ and $G_{I I c}$ are obtained from pure modes I and II experiments using corrected beam theory (Eq. (1)). For determining $\eta$, the total fracture toughness $G_{c}$ obtained through Eq. (1) for each mode mixity is plotted versus corresponding mode mix, $G_{\text {shear }} / G_{\mathrm{T}}$, values and the B-K criterion is applied over the entire range of mode mixities. The value of $\eta$ which gives the best curve fit with the B-K criterion is chosen as the $\eta$ parameter to be used in simulations. Normal and shear interfacial strengths, $\tau_{n}^{0}$, $\tau_{s}^{0}$ and $\tau_{t}^{0}$, are assumed to be close to resin strengths [47]. The required input parameters for the numerical model are summarized in Tables $3 \mathrm{a}$ and $3 \mathrm{~b}$.

\section{Results and discussion}

The developed numerical model is validated through comparison with experimental data (Figs. 7). The load versus load point displacement response obtained numerically and experimentally for three different mode mixities (30\%, 50\% and $80 \%$ ) on unidirectional laminates are presented in Fig. 7a. According to the graph, good agreement is achieved between experiments and numerical simulations especially in higher mode mixity of $80 \%$, with an error of about $7 \%$ in the maximum load prediction. The difference observed in the lower mode mixity (30\%) is caused by the difference between the experimentally measured mixed mode fracture toughness and the one determined by the specified propagation criterion (B-K) for this mode. With increasing mode mixity the critical applied load required for structural failure is also increased, since the interlaminar shear toughness of CFRP is often greater than its normal out of plane toughness as a result of extensive fracture process zone in mode II. In the numerical simulations, maximum interface damage parameter, $d$, can be tracked throughout the loading history in the specified cohesive zone. It is basically observed that this parameter starts growing at approximately

Table 3a

Mechanical properties of lamina ( $t$ : tension, $c$ : compression, is: in situ) [45].

\begin{tabular}{lllll}
\hline$E_{11}(\mathrm{MPa})$ & $E_{22}(\mathrm{MPa})$ & $v_{12}$ & $G_{12}(\mathrm{MPa})$ & $G_{23}(\mathrm{MPa})$ \\
\hline 138,000 & 10,500 & 0.3 & 6300 & 3500 \\
$X_{t}(\mathrm{MPa})$ & $X_{c}(\mathrm{MPa})$ & $Y_{t}(\mathrm{MPa}), Y_{t}^{\text {is }}(\mathrm{MPa})^{*}$ & $Y_{c}(\mathrm{MPa})$ & 3.45 \\
2070 & 1360 & $86,155^{*}$ & 196 & $G_{\text {matrix crack }}\left(\mathrm{mJ} / \mathrm{mm}^{2}\right)$ \\
\hline
\end{tabular}

Table 3b

Mechanical properties of interface.

\begin{tabular}{lllll}
\hline$\tau_{n}^{0}(\mathrm{MPa})$ & $\tau_{s}^{0}=\tau_{s}^{t}(\mathrm{MPa})$ & $K(\mathrm{MPa})$ & $G_{\mathrm{Ic}}\left(\mathrm{mJ} / \mathrm{mm}^{2}\right)$ & $G_{\mathrm{IIc}}\left(\mathrm{mJ} / \mathrm{mm}^{2}\right)$ \\
\hline 75.4 & 96.3 & $10^{7}$ & 0.98 & 2.3 \\
\hline
\end{tabular}


Table 4

Comparison of analytical and experimental results for different MD laminates.

\begin{tabular}{llll}
\hline Layup & Layup name & CTE approach, $G_{c}\left(\mathrm{~mJ} / \mathrm{mm}^{2}\right)$ & $\mathrm{Experimental,}_{c}\left(\mathrm{~mJ} / \mathrm{mm}^{2}\right)$ \\
\hline$(+22,5 /-22,5)_{s 12}$ & Layup 22.5 & 1.74 & 1.64 \\
$+45 /-45 / 0_{3} /-45 / 0 /+45 / 0_{2} /+45 /-45 / \mathbf{d} / 45 /+45 / 0_{2} /+45 / 0 /-45 / 0_{3} /-45 /+45$ & Layup 45 & 1.82 & 1.68 \\
UD $\left([0]_{24}\right)$ & Layup UD & 1.32 & 1.19 \\
\hline
\end{tabular}
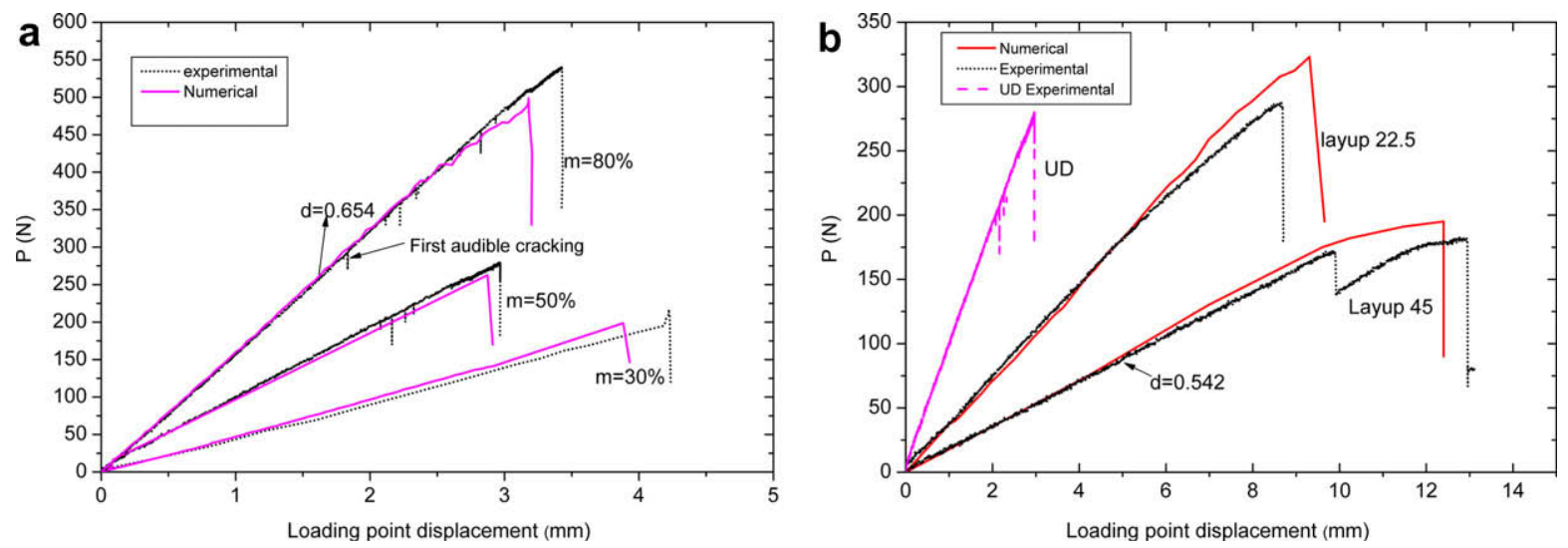

Fig. 7. (a) Numerical and experimental load-displacement response of UD laminates with different mode mixities. (b) Numerical and experimental loaddisplacement response of MD and UD laminates with $50 \%$ mode mixity.

$38 \%$ of the ultimate load, which is actually very close to the first audible cracking point. Most of the time its growth coincides with minor load drops visible on load displacement curve and it follows a faster trend closer to the ultimate load. At final failure, a number of smaller load drops precede a sudden loss of all load bearing capacity of the structure.

Fig. 7b shows the load-displacement response of multidirectional laminates subjected to MMB. It is basically observed that fiber angle orientation and stacking sequences have a global effect on load-displacement response. In the numerical model of MD laminates, in order to predict the initiation of in-ply damage correctly, the 'in situ' ply strengths must be considered. The in situ effects are characterized by higher transverse tensile and shear strengths of a ply when it is constrained by plies with different fiber orientations in a laminate, compared with the strength of the same ply in a unidirectional laminate [48-50]. In this work, the in situ tensile and shear strengths for MD laminates are estimated based on the approach suggested in Ref. [49] and replace the ones used for the UD layup. After specifying the ply and interface material parameters, obtained analytically or experimentally, FE simulations and experimental results for each layup can be compared together (Fig. 7b). The results belong to 50\% mode mixity, and a good agreement is achieved in load-displacement response with an approximate $10 \%$ error in the predicted load for the specified displacement value. The evolution of the interface damage parameter, $d$, starts at $41 \%$ of the ultimate load for layup 45 and follows a faster trend closer to the final failure, similar to the UD laminate. It is also worth mentioning that in Fig. 7a and b the elastic portion of the experiments is exactly reproduced by the numerical simulations, which also indicates the good agreement between numerical and experimental results. In other words, elastic response of the numerical simulations, representing the phase before any occurrence of damage, coincides with the experimental result. This can be achieved by adjusting the ply properties and running a few numbers of numerical simulations to obtain the correct fitted elastic properties and elastically coincident numerical and experimental results.

The conducted experiments and also the analytical solutions (Table 4) prove that the mixed mode fracture toughness of MD laminates is considerably greater than of UD ones with about 35\% increase observed in both of the mentioned layups.

First point of interest in MD laminates subjected to MMB is the blunted (curved) crack fronts observed for example in layup 45, which is considered as an extrinsic toughening mechanism [31] and will in turn improve the fracture toughness and make it difficult for the crack to propagate. However in UD laminates the crack front remains rather straight. Second point is deviation of the crack from the delamination mid-plane to the adjacent disoriented ply observed at later stages of the experiment. This will also contribute to some amount of energy absorption through in-ply damage in the adjacent layer, which again leads to an increase in the total mixed mode fracture toughness. This fact is also validated in the simulations as the orthotropic damage parameter in matrix direction, $d_{m}$, in the adjacent ply rises to 0.78 , indicating the ply is damaged in matrix direction. As mentioned earlier in Section 2.2, deviations of the delamination path from the mid-plane might invalidate the experimentally reduced data $\left(G_{I C}\right.$ and $\left.G_{I I C}\right)$. Nevertheless as the experimentally observed deviations were small and occurred in later stages of the experiment, the data reduction procedure can still be used and useful values for $G_{\mathrm{Ic}}$ and $G_{I I C}$ are obtained. Another point observed in MD laminates (layup 22.5), is the increase in the area of the fracture zone, 


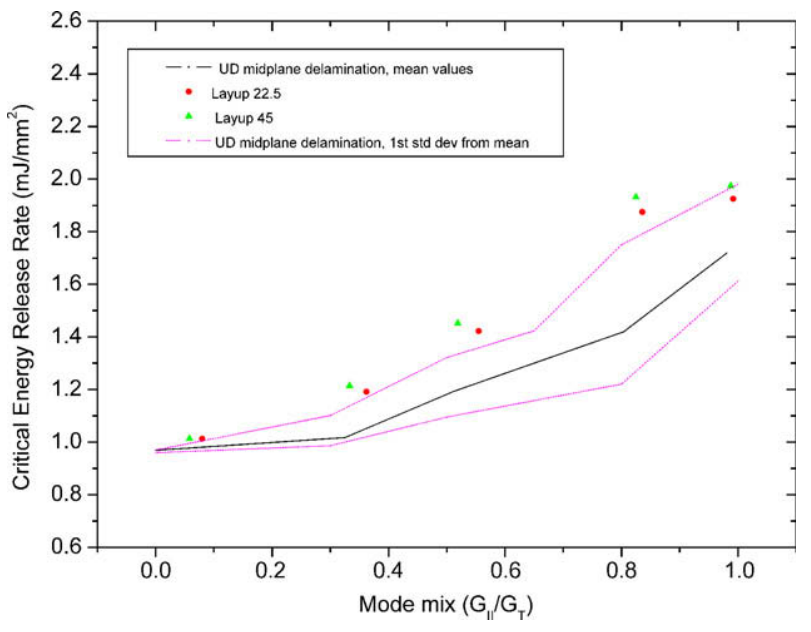

Fig. 8. Assessment of predictive capability of CTE/NSF approach for PEEK/AS4.

which is proportional to the increased delamination length. Although the mechanisms leading to this increase are not fully determined yet, this can be one of the reasons for the increase in the maximum load value in the load-displacement plots (Fig. 7b) of this layup as compared with the UD laminate [51].

Fig. 8 presents the experimentally obtained MMB delamination toughness values plotted versus mode mixities, obtained by the NSF approach as described in detail in Section 2.3 and also followed by Davidson et al. [44]. The solid and dashed lines define the basic fracture toughness curves. The reliable predictive capability of the CTE/NSF is verified in Fig. 8 by obtaining approximately a unique value of delamination toughness versus mode mix curve for three different layups (layup UD, 22.5, 45) and different mode mixities. It is observed that the CTE/NSF approach produces quite accurate predictions and can further be used as a widely applicable delamination prediction and mode-decomposition methodology as also mentioned in [44].

\subsection{Effect of $K$}

Some interface parameters such as the initial stiffness, $K$, cannot be measured directly through the experiments. Therefore, in order to find a reasonable estimation of $K$ various numerical simulations with different $K$ values were compared with experimental results as summarized in Fig. 9a. The interface stiffness should be selected large enough to provide a reasonable stiffness but also not so large to cause numerical problems such as oscillations in interfacial traction of the element. Daudeville et al. [52] have proposed the definition of the initial stiffness as the ratio of the adjacent ply stiffness in thickness direction, $E_{33}$, and the thickness of the interface, $t\left(K=E_{33} / t\right)$, which also gives a reasonable initial approximation for $K$ (Fig. 9a). Comparison of the load displacement data for various $K$ values with the corresponding experimental data indicates that as long as the initial stiffness is larger than $10^{5}$, the numerical simulations converge better. The value of $K$ is chosen as $10^{7}$ in the simulations.
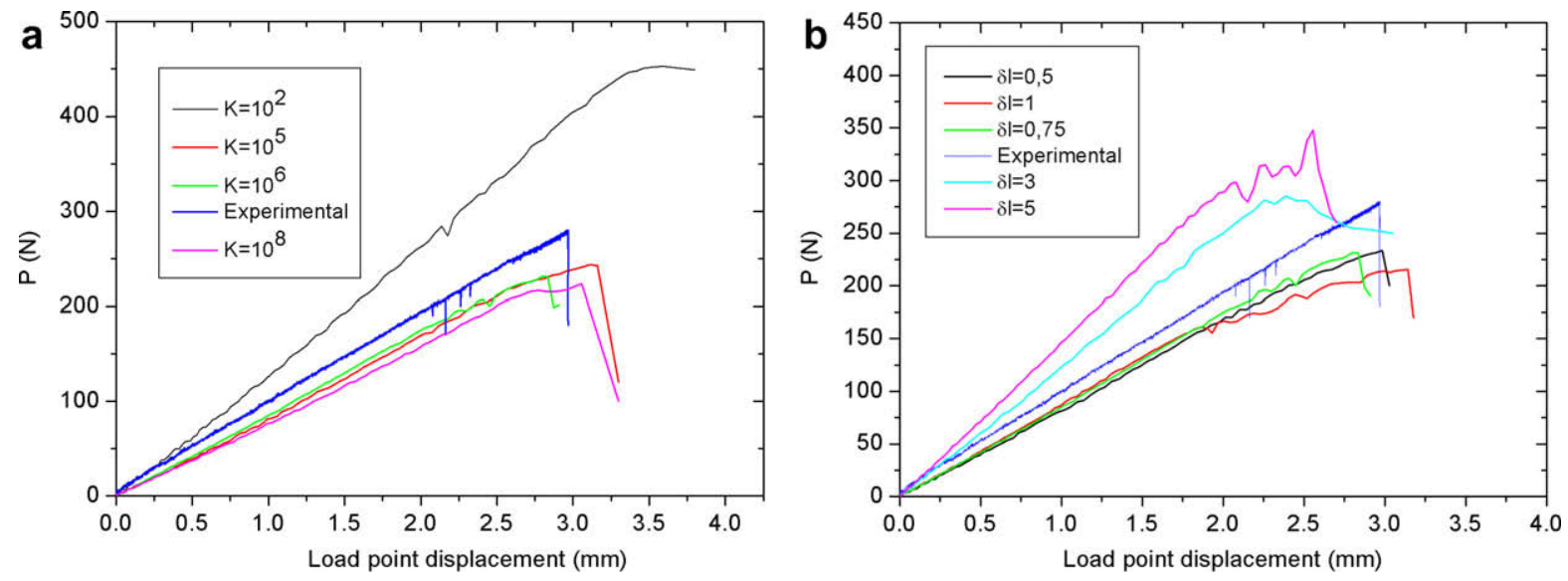

Fig. 9. (a) Effect of initial stiffness $\mathrm{K}$ on load displacement response (determination of the $\mathrm{K}$ value). (b) Effect of the cohesive element length on load displacement response (determination of the element size). 

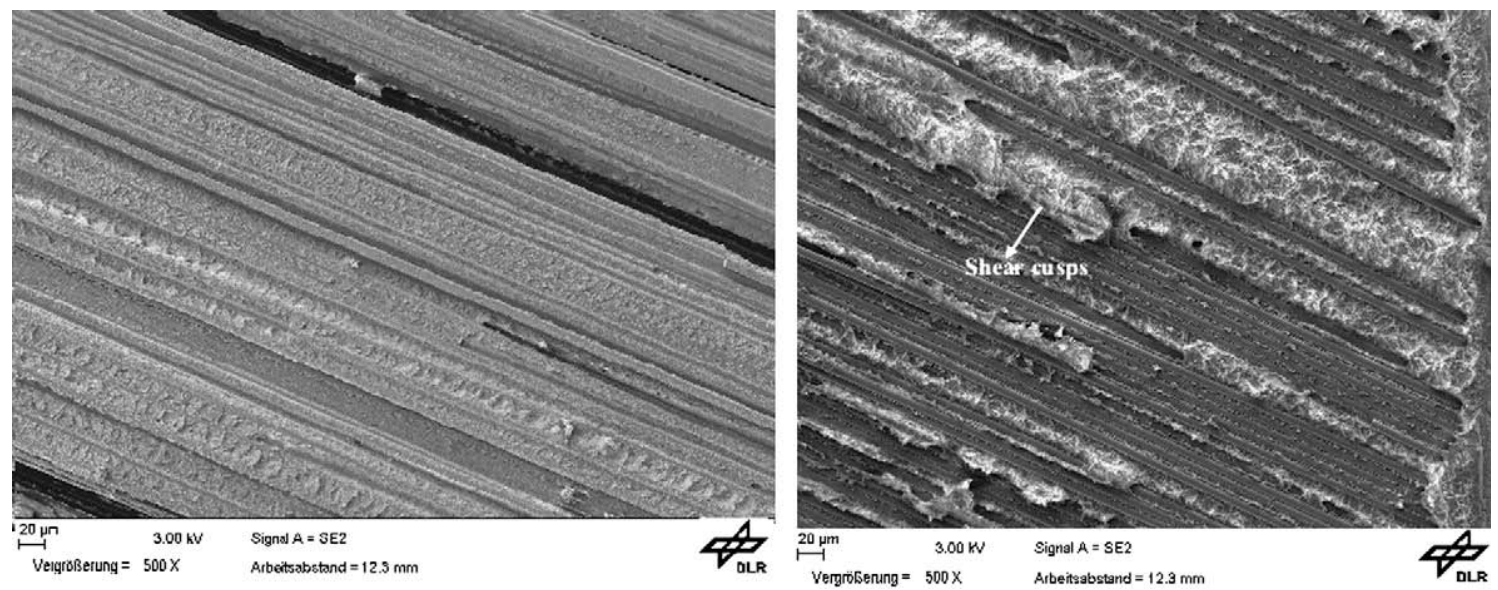

Fig. 10. Damage modes (fracture surfaces) in layup 22.5 under $30 \%$ (left) and $80 \%$ (right) mode mixities.

\subsection{Effect of $\delta l$}

In order to obtain accurate numerical results, the cohesive zone containing the interface elements must be discritized with adequate number of elements. As the cohesive zone model is a local approach, it is obvious that the solutions and obtained results are mesh dependent. Different models have been proposed in literature to estimate the length of the cohesive zone, $L_{c z}[8-10]$. The length of the cohesive zone is defined as the distance from the crack tip to the point where the final failure point is reached. In this paper, the model proposed by Hillerborg et al. [10] is used in the numerical analysis to obtain an initial estimation of the cohesive zone length and the interface element size, $\delta l$, defined by $\delta l=L_{c z} / n$ ( $n$ is the number of elements used in the cohesive zone). The performed mesh study with different element lengths is summarized in Fig. 9b. Comparisons with experimentally obtained results indicate that as long as the interface element size is taken less than $1 \mathrm{~mm}$, a better solution convergence can be achieved.

In order to show the damage modes, the fracture surface of the tested MD specimen, layup 22.5, under various mode mixities is studied via Scanning Electronic Microscopy (SEM). Fig. 10 indicates the mixed-mode damage states of layup 22.5 under $30 \%$ and $80 \%$ mode mixities. The primary difference between the fracture surfaces at different mixed mode ratios is the orientation of the appearing shear cusps. As observed in Fig. 10 (left), the fracture surface with $30 \%$ mode mixity has cusps which are randomly pulled in different directions. Larger amount of mode II, such as $80 \%$, draws the cusps more and more upward due to the increase of the mode II action (Fig. 10, right).

\section{Summary and conclusions}

This paper studies the mixed mode delamination failure in MD and UD laminates following experimental, numerical, and analytical approaches. The numerical model based on using damageable plies and interface elements has been validated successfully through comparison with experimental results for different mode mixities and various layups. Moreover, the suggested CTE approach based on CLPT and crack closure method provides a rather good estimation of the interlaminar fracture toughness of different layups when compared to experimental data. Furthermore the followed CTE/NSF approach is shown to provide relatively accurate predictions for mode decomposition and delamination growth in different layups. It can be concluded that the interlaminar mixed mode fracture toughness of MD laminates increases considerably compared to UD ones as a result of some observed extrinsic toughening mechanisms. Moreover, the amount of this increase can also be estimated using the mentioned analytical CTE approach. The sensitivity of the interface element has also been tested with respect to two input parameters: the initial interface stiffness, $K$, and the element size, $\delta l$, using some numerical examples. The numerical results revealed that in order to achieve a closer response to experimentally obtained results there must be some limitations on the values of $K$ and $\delta l$, which in turn influence the computational cost of the simulation. It is also significant that all interface parameters must be specified correctly in order to avoid long computational times, or solution oscillations and obtain better solution convergence. The implemented interface elements are further planned to be placed in the Ti-CFRP interface of a multidirectional Ti-CFRP hybrid structure subjected to mixed mode delamination.

\section{Acknowledgements}

The authors acknowledge the effort of the technicians and co-workers in the institute of Structure and Design of DLR, Stuttgart for producing the CFRP laminates and the experimental department for conducting the experiments. 


\section{References}

[1] Ladeveze P, Le Dantec E. Damage modelling of the elementary ply for laminated composites. Compos Sci Technol 1992;43:257-67.

[2] Matzenmiller A, Lubliner J, Taylor RL. A constitutive model for anisotropic damage in fiber composites. Mech Mater 1995;20:125-52.

[3] Herakovich CT. Mechanics of fibrous composites. New York: Wiley; 1998.

[4] Allix O, Leveque D, Perret L. Interlaminar interface model identification and forecast of delamination in composite laminates. Compos Sci Technol 1998;56:671-8.

[5] Hashin Z. Failure criteria for unidirectional fiber composites. J Appl Mech 1981;20:329-34.

[6] Rice JR. A path independent integral and the approximate analysis of strain concentrations by notches and cracks. J Appl Mech 1968;35:379-86.

[7] Rybicki EF, Kanninen MF. A finite element calculation of stress intensity factors by a modified crack closure integral. Engng Fract Mech 1977;9:931.

[8] Dugdale DS. Yielding of steel sheets containing slits. Nonlinear Dynam 1960;8:100-4.

[9] Barenblatt GI. The mathematical theory of equilibrium cracks in brittle fracture. Adv Appl Mech 1962;7:55-129.

[10] Hillerborg A, Modeer M, Petersson PE. Analysis of crack formation and crack growth in concrete by means of fracture mechanics and finite elements. Cem Concr Res 1976;6:773-82.

[11] Foulk JW, Allen DH, Helms KLE. Formulation of a three dimensional cohesive zone model for application to a finite elements algorithm. Comput Meth Appl Mech Engng 2000;183(1-2):51-67.

[12] Ladeveze P, Guitard L, Champaney L, Aubard X. Debond modeling for multidirectional composites. Comput Meth App Mech Engng 2000;183(12):109-22.

[13] Allix O, Blanchard L. Mesomodeling of delamination: towards industrial applications. Compos Sci Technol 2006;66:731-44.

[14] Borg R, Nilsson L, Simonsson K. Modeling of delamination using a discretized cohesive zone and damage formulation. Compos Sci Technol 2002;62:1299-314.

[15] Alfano G, Crisfield MA. Finite element interface models for delamination analysis of laminated composites: mechanical and computational issues. Int J Numer Meth Engng 2001;50:1701-36.

[16] Davila CG, Camanho PP, de Moura MFSF. Mixed-mode decohesion elements for analyses of progressive delamination. In: Proceedings of the 42nd AIAA/ASME/ASCE/AHS/ASC structures. Structural dynamics and materials conference, Seattle, Washington, April 16-19; 2001.

[17] Turon A, Camanho PP, Costa J, Davila CG. A damage model for the simulation of delamination under variable-mode loading. Mech Mater 2006;38:1072-89.

[18] Kruger R, Konig M. Effect of stacking sequence on energy release rate distributions in multidirectional DCB and ENF specimens. Engng Fract Mech 1996;55(4):557-69.

[19] Davidson BD, Kruger R, Konig M. Three dimensional analysis and resulting design recommendations for unidirectional and multidirectional end notched flexure tests. J Compos Mater 1995;29:2108-33.

[20] Wang SS, Choi I. The interface crack between dissimilar anisotropic composite materials. J Appl Mech 1983;50.

[21] Prombut P, Michel L, Lachaud F, Barrau JJ. Delamination of multidirectional composite laminates at $0 / \theta$ ply interfaces. Engng Fract Mech 2006;73:2427-42.

[22] Ozdil F, Carlsson LA. Beam analysis of angle-ply laminate mixed-mode bending specimens. Compos Sci Technol 1999;59:937-45.

[23] Choi NS, Kinloch AJ, Williams JG. Delamination fracture of multidirectional carbon-fiber/epoxy composites under mode I, mode II and mixed-mode I/II loading. J Compos Mater 1999;33:73-100.

[24] Ploaha JJ, Davidsin BD, Hudson RC, Pieracci A. Effects of mode ratio, ply orientation and precracking on fracture toughness of a laminated composite. J Reinf Plast Compos 1996;15:141-73.

[25] Pereira AB, de Morais AB. Mixed mode I + II interlaminar fracture of glass/epoxy multidirectional laminates. Part I: analysis. Compos Sci Technol 2004;35:265-72.

[26] Scharpery RA, Davidson BD. Prediction of energy release rate for mixed mode delamination using plate theory. Appl Mech Rev 1990;43(5):part.

[27] Davidson BD, Hurang Hu. An analytical crack tip element for layered elastic structures. Trans ASME 1995:62.

[28] Davidson BD, Gharibian SJ, Yu L. Evaluation of energy release rate based approaches for predicting delamination growth in laminated composites. Int J Fract 2000;105(4):343-65.

[29] Gilchrist MD, Svensson N. A fractographic analysis of delamination within multidirectional carbon/epoxy laminates. Compos Sci Technol 1995;55:195-207.

[30] Kelly G, Hallstrom S. Strength and failure mechanisms of composite laminates subject to localised transverse loading. Compos Struct 2005;69:301-14.

[31] Hertzberg RW. Deformation and fracture mechanics of engineering materials. New York: Wiley; 1996.

[32] Piggot MR, Zhang W. Fracture toughness of angle ply laminates. ESIS Fract Polym Compos Adhes II 2003;32:445-54.

[33] Crews JH, Reeder JR. A mixed-mode bending apparatus for delamination testing; 1988: NASA TM 100662.

[34] Reeder JR, Crews JH. Nonlinear analysis and redesign of the mixed-mode bending delamination test; 1991. [NASA TM 102777].

[35] ABAQUS 6.6 user's manuals. Pawtucket, USA: Hibbitt, Karlsson, and Sorensen, Inc.; 1996.

[36] Jones Robert M. Mechanics of composite materials. New York; McGraw-Hill.

[37] Standard test method for mode I interlaminar fracture toughness of unidirectional fiber reinforced polymer matrix composites. ASTM standard D 5528-94a, ASTM annual book of standards, vol. 15.03; 1994. p. 272-81.

[38] Adams DF, Carlsson LA, Pipes RB. Experimental characterization of advanced composite materials. 3rd ed. Boca Raton: CRC Press; 2003.

[39] Test Method D6671-01. 2002. Standard test method for mixed mode I/ mode II interlaminar fracture toughness of unidirectional fiber reinforced polymer matrix composites. ASTM. PA. USA.

[40] Williams JG. The fracture mechanics of delamination tests. J Strain Anal 1989;24:207-14.

[41] Pereira AB, de Morais AB. Mixed mode I+II interlaminar fracture of carbon/epoxy multidirectional laminates. Compos Sci Technol 2008;39:322-33.

[42] Ducept F, Davis P, Gamby. An experimental study to validate tests used to determine mixed mode failure criteria of glass epoxy composites. Composites: Part A 1997;28(A):719-29.

[43] Benzeggagh ML, Kenane M. Measurement of mixed-mode delamination fracture toughness of unidirectional glass/epoxy composites with mixedmode bending apparatus. Compos Sci Technol 1996;56:439-49.

[44] Davidson BD, Bialaszewski RD, Sainath S. A non-classical, energy release rate based approach for predicting delamination growth in graphite reinforced laminated polymeric composites. Compos Sci Technol 2006;66:1479-96.

[45] Internal report: mechanical properties of PEEK/AS4. Source: CYTEC/DLR. Stuttgart: Institute of Structures and Design, DLR.

[46] Standard test method for plane-strain fracture toughness of metallic materials. ASTM E399 - 90, Annual bookof ASTM standards, vol. 03.01; 1993. p. 407-528.

[47] Liu K, Piggott MR. Fracture failure processes in polymers I: mechanical tests and results. Polym Engng Sci 1998;38:60-8.

[48] Dvorak GJ, Laws N. Analysis of progressive matrix cracking in composite laminates: - II first ply failure. J Compos Mater 1987;21:309-29.

[49] Davila CG, Camanho PP, Rose CA. Failure criteria for FRP laminates. J Compos Mater 2005;39(4):323-45.

[50] Flaggs DL, Kural MH. Experimental determination of the in situ transverse lamina strength in graphite/epoxy laminates. J Compos Mater 1982;16:103-16.

[51] Brunner AJ, Flueler P. Prospects in fracture mechanics of engineering laminates. Engng Fract Mech 2005;72:899-908.

[52] Daudeville L, Allix O, Ladevèze P. Delamination analysis by damage mechanics: some applications. Compos Engng 1995;5(1):17-24. 